\title{
The Role of Silver (Ag) Nanoparticles synthesis by Penicillium spp against the Toxicity of Echinococcus Granulosus in Adult Albino Male Rats
}

\author{
Ahmed Hamad Saleh ${ }^{1}$ Hussein A.R. Abbood ${ }^{1}$ \\ ${ }^{1}$ Medical Analysis department/ Al-Qalam College /Kirkuk/Iraq
}

\begin{abstract}
The aim of the study was to synthesize Ag nanoparticles by using filamentous fungus

Penicillium $s p$. The fungal culture was isolated from the soil samples collected from agriculture fields in Kirkuk city. The synthesis of silver nanoparticles was investigated by X-ray difraction peaks were measured at (101), (200) and (202) respectively, and scanning electron microscopy .

The present study was designed to indicated the role of Ag nanoparticles synthesis by Penicillium spp against toxicity of Echinococcus granulosus. The present study used twenty adult albino male rats that distributed at random to following teams (each group consist five rats); management group received ad libidium, second group injected with 2,5 $\times 10^{3}$ of Echinococcus granulosus protoscolices third group injected with protoscolices and treatd with $50 \mathrm{mg} / \mathrm{kg}$ AgNanoPs, fourth group injected with protoscolices and treatd with $100 \mathrm{mg} / \mathrm{kg} \mathrm{AgNanoPs}$. The results show high important exaggerated $(\mathrm{P}<0.05)$ in levels of MDA (malonedialdehyied) and important decrease $(\mathrm{P}<0.05)$ in levels of glutathione $(\mathrm{GSH})$ and catalasce compared with management group. While, after used AgNPs with Echinococcus granulosus, the results indicated non-significant changes $(\mathrm{P}<0.05)$ in MDA, GSH and catalse also showed non-significant changes $(\mathrm{P}<0.05)$ compared with control group. histological study show decrease in numbers of spermatogonia and spermatocytes with absent of spermatid. While, after using AgNPs the testis in third and fourth groups appear semi-normal. It had been ended that AgNanoPs has been potential role against tocxicity of Echinococcus granulosus in rats male.
\end{abstract}

Keywords: Ag nanoparticles; Echinococcus granulosus; testis.

\section{Introduction}

Cystic Echinococcosis (CE) is one of the most important zoonotic helminthic diseases throughout the world (1). The larval stage of the Echinococcus granulosus leads to hydatidosis (2). Adult worms live in the small intestine of canids as definitive hosts with a high prevalence in the world $(3,4)$. Intermediate hosts include humans as well as cows, sheep, camels, horses et al that acquire the infection by oral uptake of tapeworm eggs. once intake by appropriate host and sequent passage through abdomen and intestinal, the oncosphere brute become activated, penetrate the tissue layer, enter to the blood stream and body fluid vessels and area unit disseminated within the body. once associate indefinable time period, E. granulosus metacestodes area unit shaped $(1,5)$. Nano-biotechnology is presently one among the foremost dynamic disciplines of analysis in modern material science whereby plants and totally different plant merchandise ar finding an important use within the synthesis of nanoprticles (NPs) (6, 7). in nano-biotechnological analysis, AgNPs have received important attention owing to their distinctive physical chemical, biological properties, and since of their pertinence in natural philosophy, optics and drugs (8). Among diverse nanaoparticles, Ag nanoparticles because various properties like chemical change, chemical science conduction and antimicrobial activity, are often employed in completely different applications like biomedicine, agriculture, icon chemicals and food chemistry $(9,10)$. The present study was designed to indicate the role of green $\mathrm{Ag}$ nanoparticles againsted toxicity of Echinococcus granulosus. 


\section{Materials \& Method}

\section{Animal model}

In this study twenty adult male albino rats, (wt 225275 gm with age4-6 month) obtained from Technicals colleege/ North Technical Univerisity, and unbroken on customary pellete diet for week to insure its normal.

\section{Isolation sample}

Soil samples were obtained from town of city. For soil suspension preparation, $\mathrm{CaCO} 3$ was treated with one 0: 1 weight / weight and incubated in brooder at thirty seven ${ }^{\circ} \mathrm{C}$ for four days. For drying functions, a series of ten - so took 0.5 milliliter of dilutions 10-3.10.4 and placed in sterile Petri dishes and poured within the middle of the sterile PDA and fluid to (50-45) $\mathrm{m}$ and stirred the dish to homogenize the soil answer with the middle of the plant so incubated for 6-4 days when uninflected the isolates and diagnosing, looking on.

\section{Preparation of fungal biomass and composition of silver nanoparticles}

The fungal fungus was prepared by taking a tablet of the clean, pure fungal colony using a $7 \mathrm{~mm}$ sterile veneer hole, where the developing colony edges were punctured on the fungal growth plate and placed in a 100 $\mathrm{mL}$ conical flask of the liquid MYPG medium where it was quietly placed to the disc on the center surface After a period of time, the disk stabilized on the surface of the liquid medium, and then placed in the incubator at 26 ${ }^{\circ} \mathrm{C}$ for 5-7 days to obtain a mat with different weights (11). After the fungus was nominated the fungal mass using the filter paper( Whatman filter paper NO 1) And then rinsed thoroughly with distilled water to remove the residue of the medium. The fungal flask was then placed in a conical flask containing $100 \mathrm{ml}$ of distilled distilled water and left for 72-24 hours in the incubator. The fungal mass was again filtered using filter paper to ensure that all components of the medium were removed. Filtration in an electric oven of Memmert (Germany) at a temperature of $50 \mathrm{~m}$. The dry weight of the fungus was measured by weight between the dried paper mass with its contents after filtration and the filter paper block. It was dried before filtration. $10 \mathrm{~g}$ of fungal mass and then placed in $100 \mathrm{ml}$ of Ag NO3 prepared silver nitrate With a concentration of $1 \mathrm{mM}$ and placed in the incubator In completely dark conditions and after chromatography, AgNPs were examined x-ray shimadzu during a laboratory within the academic department - school of

Science, University Bagdad. The scanning microscopy SEM (Scaning negatron Microscopy) (TESCANVEGA) was conjointly employed in the engineering center.

\section{Echinococcus granulosus}

hydatid cysts were collected and obtained from infected sheep livers. They were put in plastic bags, and transported to the Department of biological science, school Technical, North Technical University, wherever protoscolices were isolated from livers in keeping with (12) technique . Protoscolices indicates the fertility of hydatid cyst and it's were counted according to method cited by(13). cyst and it's were counted in keeping with technique cited by (13). The viable protoscolices for parasite were counted in oneml from supernatal supported the formula : Viability in 1 metric capacity unit $=$ variety of protoscolices in $(10 \mu \mathrm{l}) \times$ one hundred.

\section{Experimental design}

Twenty adult male albino rats were used and divided as follow (each groupe consist 5 rats):

management group: rats were received normal pellet diet just for seven days so killed..

Positive group rats injected with protoscolices, and so killed.

Third group rats injected with protoscolices and treated with $50 \mathrm{mg} / \mathrm{kg} \mathrm{Ag} \mathrm{NanoPs}$ for month, and so killed.

Fourth group rats injected with protoscolices and treated with $100 \mathrm{mg} / \mathrm{kg} \mathrm{Ag}$ NPs for month, and then killed.

\section{Prepare of blood solution}

The blood collection from rats by internal organ puncher, below anaesthesia, and place in check tubes . After clotting, the tubes were activity for ten min to get sera. The bodily fluid was taken and hold on by deep phase transition till used.

\section{Homogenization}

Testis samples were removed immediately and the put in glass dish contents $0.9 \% \mathrm{NaCl}$ buffer for washing and removed the blood. To oxidative stress factors determination, $10 \%$ from organ weight was dissolved with buffer (PH 7.4) and the organ tissue was crashed 
by use ceramic mortar. Then mixture was centerfigation for $10 \mathrm{~min}$. Supernated was taken and stored by deep freezing till used (14).

\section{Measurements}

\section{Plasma Peroxidation levels (MDA), Glutathione (GSH) and Catalase}

MDA (malonedialdehyied), was measured based on the quantitative chemical analysis reaction with thiobarbituric acid (TBA) exploitation photometer (15). GSH level calculable bymixed two. 3 cubic centimeter buffer with zero. $2 \mathrm{ml}$ of the sample and so side zero. $5 \mathrm{ml}$ of 5,5-dithio-bis-(2-nitrobenzoic acid) (DTNB).The mixture was analyzed by spectrophotometer(16). Catalase was measured by using the procedurce of Biovision-USA kits.

\section{Histological study}

testis biopsies were soft on $4 \mathrm{~mm}$ punch and $2 \%$ xylocaine was used as an anesthetic. The biopsies were mounted in 10\% formalin, habitually processed and embedded in paraffin sections that were stained with hematoxylin and fluorescent dye andand examined under the microscope.

\section{Statistical Analysis}

the info were analyzed employing a applied math Minitab program. A applied math distinction between the suggests that of the experimental teams was analyzed exploitation a way analysis of variance (ANOVA). Results

\section{Isolation and identification of Penicillium sp.}

Fungal cultures were isolated from the soil samples collected from varied agricultural lands in kirkuk city. The fungus isolates were characterised on the premise of colony characteristics and microscopic look (17). genus Penicillium sp colonies appeared as velvety and fissure with inexperienced color on personal organiser medium plates. Reverse aspect of the colony was yellow in color. Results are displayed in Figure1. Microscopic identification of the plant isolates was performed by LPCB mounting. genus Penicillium sp. appeared as extremely branched mycilium part, septal hyphae. Conidiphores up on the mycelium part and conidiospores were unreal.

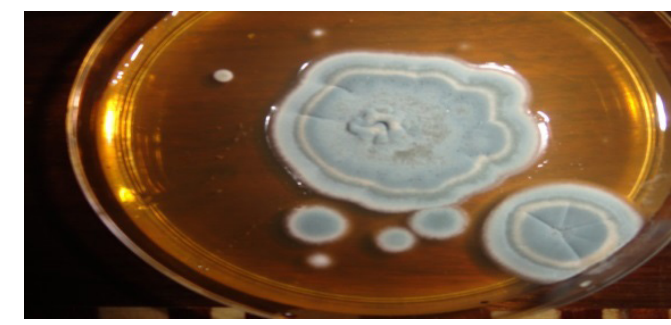

Figure 1: Colony morphology of the Penicillium sp. isolate

Characterization of silver nanoparticles Color amendment Cell free filtrate of Penicillium $s p$. was mixed with caustic resolution and incubated in dark in rotary shaker. Samples showed modified in color from virtually colourless to brown, this is often a transparent indication of the formation of silver nanoparticles within the reaction mixture. The intensity of the color was accumulated throughout the amount of incubation. the looks of brown color was because of the excitation of surface plasmon vibrations(18).

\section{X-Ray differentiation analysis}

The XRD pattern therefore clearly shows that the conductorNO3 nanoparticles fashioned by the reduction of $\mathrm{Ag}$ ions by fungus genus sp are crystalline in nature (Figure 2). Our results similar output was obtained by $(19,20)$

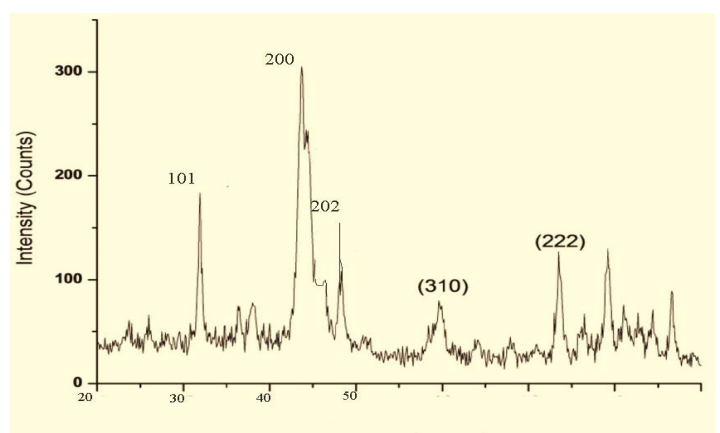

Figure (2) XRD of silver nanoparticles mistreatment genus Penicillium sp .

\section{Scanning Electron Microscope}

The dried silver nanoparticles were obtained by action at 10000 rev for twenty mts. the scale and form of the silver nanoparticles biosynthesized was studied by SEM as in figure 3 . 


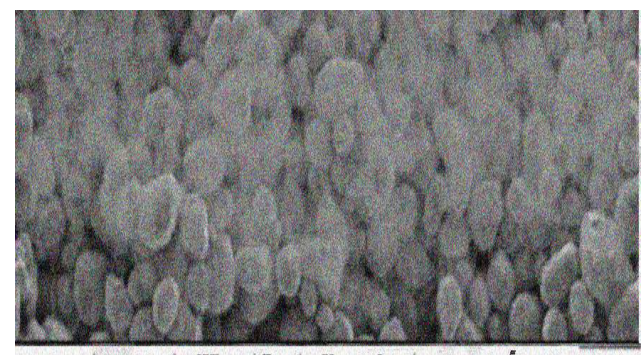

HV | Mag | WD | Det $\mid$ Vac mode

$10.00 \mathrm{kw} / 22000 \times 18.30 \mathrm{~mm}$ ETD High vacuum

Figure (3)SEM image of silver nanoparticles.

Oxidative stress (MDA) \& antioxidant parameters (GSH and catalase) in testis

The levels of MDA (2.18 \pm 0.37$)$, GSH $(0.139 \pm$ $0.025)$ and enzyme catalase $(0.46 \pm 0.07)$ in second group show high significant changes $(\mathrm{P}<0.05)$ compared with management rats $(1.24 \pm 0.11 ; 0.276 \pm$ 0.043 and $1.16 \pm 0.02$ respectively). The levels of MDA $(1.38 \pm 0.2 ; 1.27 \pm 0.16$ respectively $), \mathrm{GSH}(0.252 \pm$ $0.031 ; 0.294 \pm 0.052$ respectively) and catalase $(1.03 \pm$ $0.04 ; 1.11 \pm 0.03$ respectively) in third and fourth groups show non-significant changes $(\mathrm{P}<0.05)$ compared with management rats as shown in table (1).

Table (1): The levels of MDA, GSH and CAT in testis

\begin{tabular}{|l|l|l|l|}
\hline $\begin{array}{l}\text { Parameters } \\
\text { Groups }\end{array}$ & $\begin{array}{l}\text { MDA } \\
(\mathbf{m m o l} / \mathbf{l})\end{array}$ & $\begin{array}{l}\text { GSH } \\
(\mathbf{m o l} / \mathbf{l})\end{array}$ & $\begin{array}{l}\text { Cata } \\
\mathbf{( m m o l} / \mathbf{l})\end{array}$ \\
\hline Control group & $\begin{array}{l}1.24 \pm \\
0.11 \mathrm{~b}\end{array}$ & $\begin{array}{l}0.276 \pm \\
0.043 \mathrm{a}\end{array}$ & $\begin{array}{l}1.16 \pm \\
0.02 \mathrm{a}\end{array}$ \\
\hline Second group & $\begin{array}{l}2.18 \pm \\
0.37 \mathrm{a}\end{array}$ & $\begin{array}{l}0.139 \pm \\
0.025 \mathrm{~b}\end{array}$ & $\begin{array}{l}0.46 \pm \\
0.07 \mathrm{~b}\end{array}$ \\
\hline Third group & $\begin{array}{l}1.38 \pm \\
0.2 \mathrm{~b}\end{array}$ & $\begin{array}{l}0.252 \pm \\
0.031 \mathrm{a}\end{array}$ & $\begin{array}{l}1.03 \pm \\
0.04 \mathrm{a}\end{array}$ \\
\hline Fourth group & $\begin{array}{l}1.27 \pm \\
0.16 \mathrm{~b}\end{array}$ & $\begin{array}{l}0.294 \pm \\
0.052 \mathrm{a}\end{array}$ & $\begin{array}{l}1.11 \pm \\
0.03 \mathrm{a}\end{array}$ \\
\hline
\end{tabular}

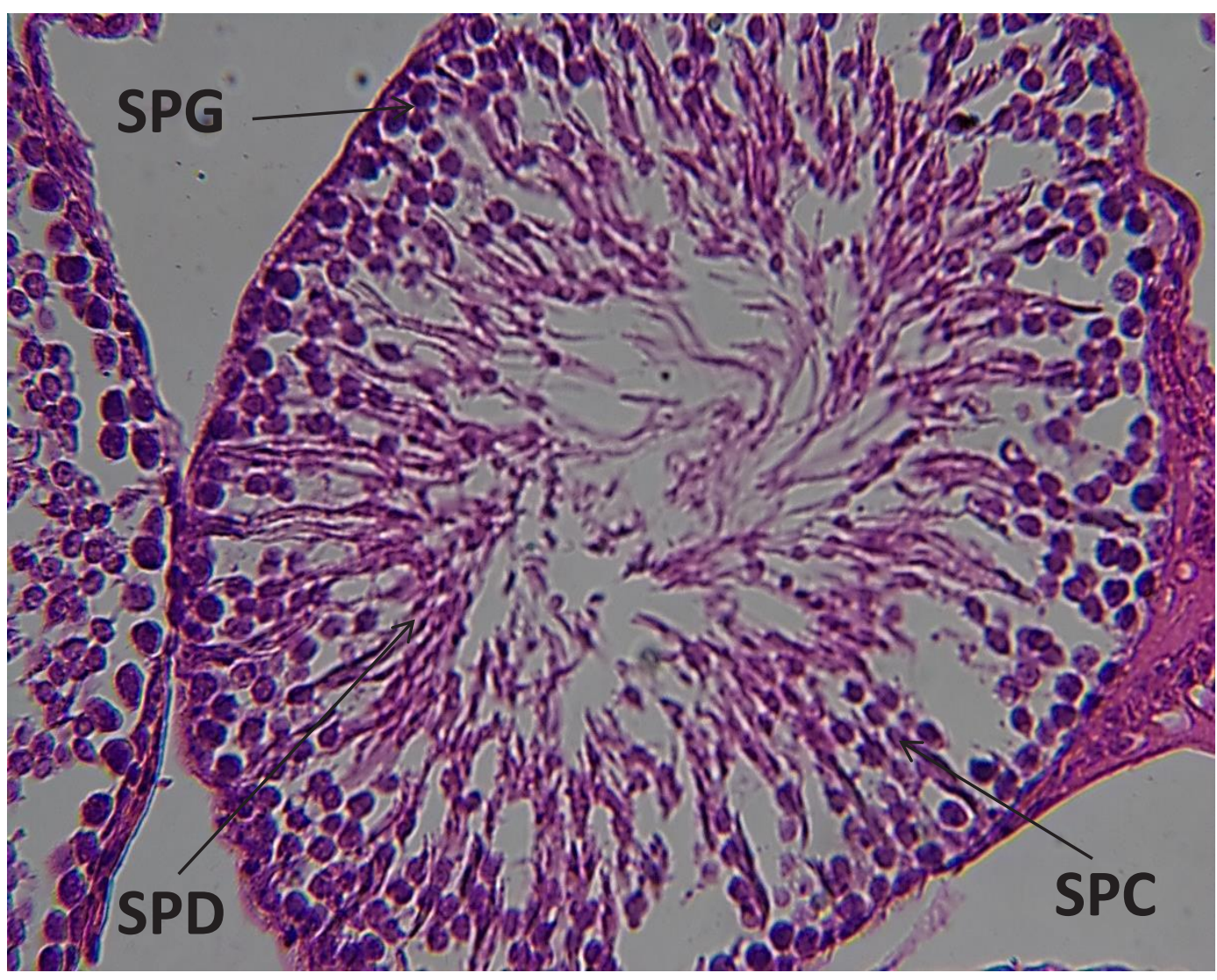

Figure (4): testis of control group show spermatogonia (SPG), spermatocytes (SPC) and gamete (SPD). H\&E X400. 


\section{Histological study}

The sections that prepared with control group that show normal in normal structure of spermatogonia, spermatocytes and spermatids as shown in figure (4). The sections that prepared from third and fourth groups show a semi-normal structure spermatogonia, spermatocytes and spermatids as shown in figure (5).

\section{Discussion}

The results of present study increased in levels of MDA and decrease in levels of glutathione (GSH) and enzyme catalase in second group that infected with $E$. granulosus With decrese in numbers of spermatogonia and spermatocytes. The results is in agreement with (21) who referred that the infection with Echinococcus granulosus lead to eleveated the levels of MDA, where found the mean +/- SD of MDA levels of patients with Echinococcus granulosu(21). On the other hand, (22) referred that E. granulosus lead to decrese in numbers of spermatogonia and spermatocytes that is in agreement with present study (22). About the treatment and the role of AgNPs. many study show the ability of AgNPs as antimicrobial against different bacteria (S.aureus, E.faecalis, Pseudomonas and E.coli) (23). The bactericidal activity of nanoparticles is associated with alternative ways by direct react with microbial cells or effect on metabolic process lepton transport from biological process that inhibits respiratory chain enzymes or interferes through covering porousness to phosphate and protons(24) .Finally, the present study show after using AgNPs decrese in MDA and increase levels of GSH and catalase suggest the possibility of using Ag NPs as an anti-oxidant agent by inhibition the formation of free radicals and scavenging all species of (ROS) (25).

Ethical Clearance: The Research Ethical Committee at scientific research by ethical approval of both environmental and health and higher education and scientific research ministries in Iraq

Conflict of Interest: The authors declare that they have no conflict of interest.

Funding: Self-funding

\section{References}

1. Ahmadnia S, Moazeni M, Mohammadi-Samani $\mathrm{S}$. Hydatid cyst formation in male Balb/c mice following the intraperitoneal injection of live protoscoleces and activated oncospheres: a comparative study. Journal of parasitic diseases. 2014;38(1):77-80.

2. Rafiei A, Asgarian F, Rahdar M, Jelowdar A, Sabaghan M. Experimental hydatid cyst development in different breeds of mice: A reevaluation. 2017.

3. Deplazes P, Rinaldi L, Rojas CA, Torgerson P, Harandi M, Romig T, et al. Global distribution of alveolar and cystic echinococcosis. Advances in parasitology. 95: Elsevier; 2017. p. 315-493.

4. Rahimi HR, Mohammadzadeh T, Sadjjadi SM, Sarkari B, Zahabiun F. BALB/c Mice Immunity to Hydatidosis Induced by In-vitro Reared Echinococcus granulosus Adult Worm Antigens. Iranian Journal of Immunology. 2017;14(2):123-33.

5. Chyiad AL, Muhsin SS, Ahmed DN. Comparison of Three DNA Extraction Methods for Detection Echinococcus granulosus Isolated from Sheep and Cows. Journal of the Faculty of Medicine. 2018;60(1):62-4.

6. Billacura MP, Mimbesa HS. 026: leaf extract mediated green synthesis of silver nanoparticles from widely available Wedelia trilobata: synthesis, partial characterization and antimicrobial property analysis. British Medical Journal Publishing Group; 2015.

7. Banerjee P, Satapathy M, Mukhopahayay A, Das P. Leaf extract mediated green synthesis of silver nanoparticles from widely available Indian plants: synthesis, characterization, antimicrobial property and toxicity analysis. Bioresources and Bioprocessing. 2014;1(1):3.

8. Okafor F, Janen A, Kukhtareva T, Edwards V, Curley M. Green synthesis of silver nanoparticles, their characterization, application and antibacterial activity. International journal of environmental research and public health. 2013;10(10):5221-38.

9. Allafchian A, Bahramian H, Jalali SAH, Ahmadvand H. Synthesis, characterization and antibacterial effect of new magnetically core-shell nanocomposites. Journal of Magnetism and Magnetic Materials. 2015;394:318-24.

10. Allafchian A, Mirahmadi-Zare S, Jalali S, Hashemi S, Vahabi M. Green synthesis of silver nanoparticles using phlomis leaf extract and investigation of their antibacterial activity. Journal of Nanostructure 
in Chemistry. 2016;6(2):129-35.

11. Karbasian M, Atyabi S, Siadat S, Momen S, Norouzian D. Optimizing nano-silver formation by Fusarium oxysporum PTCC 5115 employing response surface methodology. American journal of Agricultural and biological science. 2008.

12. Guarnera EA, Parra A, Kamenetzky L, García G, Gutiérrez A. Cystic echinococcosis in Argentina: evolution of metacestode and clinical expression in various Echinococcus granulosus strains. Acta tropica. 2004;92(2):153-9.

13. Al-Humairy A. Evaluation of the activity Daturastramonium seeds extracts on growth and development of hydatid cysts for echinococcusgranulosus in white mice Balb/c (Therapeutic, Histologic and Immunologic Study) PhD Thesis. College of Science, Kufa University. 2010.

14. Albir AA. Histological Changes in The Liverof Mice Treated with Cadmium. Iraqi Journal of Science. 2013;54(1):50-4.

15. Ali AA, Alattar SA. Study the protective effect of Matricaria chamomilla flower extract against the toxicity of Entamoeba histolytica induces liver and renal dysfunctions in adult albino male rats. Iraqi Journal of Science. 2018;59(2B):832-8.

16. Mahmood NA. Glutathion-S-transferase Enzyme and Malondialdehyde (MDA) in colorectal cancer and in healthy control. Iraqi Journal of Cancer and Medical Genetics. 2010;3(1):21-7.

17. Cappuccino J, Sherman N. Microbiology: a laboratory manual, Dorling Kindersley (India) Pvt. Ltd, India. 2006;6:237.

18. Ahmad A, Mukherjee P, Senapati S, Mandal D, Khan MI, Kumar R, et al. Extracellular biosynthesis of silver nanoparticles using the fungus Fusarium oxysporum. Colloids and surfaces B: Biointerfaces. 2003;28(4):313-8.

19. Gnanajobitha G, Rajeshkumar S, Kannan C, Annadurai G. Preparation and characterization of fruit-mediated silver nanoparticles using pomegranate extract and assessment of its antimicrobial activity. J Environ Nanotechnol. 2013;2(1):04-10.

20. Sivakumar J, Premkumar C, Santhanam P, Saraswathi N. Biosynthesis of silver nanoparticles using Calotropis gigantean leaf. African Journal of Basic \& Applied Sciences. 2011;3(6):265-70.

21. Koltas IS, Yucebilgic G, Bilgin R, Parsak CK, Sakman G. Serum malondialdehyde level in patients with cystic echinococcosis. Saudi medical journal. 2006;27(11):1703-5.

22. Al-Makki AQ. A study of the Cisplatin effect on testis of Infected mice with Echinococcus granulosus. JOURNAL OF THI-QAR SCIENCE. 2012;3(3):59-66.

23. Mahmood MA. The antibacterial effect of silver nanoparticles on some bacterial pathogens. Iraqi Journal of Physics. 2012;10(18):56-61.

24. Al-Bahrani RM, Ghafil JA. Evaluation of inhibition activity of silver nanoparticles activity against pathogenic bacteria. Iraqi Journal of Science. 2016;57(3C):2203-7.

25. Al-Mashhadani AH, Yas RM. Silver nanoparticles as free radical scavengers for protection from nuclear radiation hazards. Engineering and Technology Journal. 2015;33(6 Part (B) Scientific):1110-9. 